\title{
Developing Digital Educational Materials
} for Nursing and Sustainability: The results of an observational study

\author{
Alvarez Nieto, C \\ http://hdl.handle.net/10026.1/10119
}

10.1016/j.nedt.2017.10.008

Nurse Education Today

Elsevier

All content in PEARL is protected by copyright law. Author manuscripts are made available in accordance with publisher policies. Please cite only the published version using the details provided on the item record or document. In the absence of an open licence (e.g. Creative Commons), permissions for further reuse of content should be sought from the publisher or author. 
This is the authors' accepted manuscript. The final published version of this work is published by Elsevier in Nurse Education Today (November 2017) available at https://doi.org/10.1016/j.nedt.2017.10.008. This work is made available online in accordance with the publisher's policies. Please refer to any applicable terms of use of the publisher.

Carmen Alvarez Nieto, Ph.D.; Janet Richardson, PhD; Gema Parra-Anguita, PhD; Manuel Linares-Abad, PhD; Norma Huss, PhD; M Luisa Grande-Gascón, PhD; Jane Grose, PhD; Maud Huynen, PhD; Isabel M López-Medina, PhD

\section{Title: Developing Digital Educational Materials for Nursing and Sustainability: The results of an observational study}

\section{INTRODUCTION}

The World Health Organization estimates that, in 2012, 12.6 million people died because of an unhealthy environment, and that environmental risk factors, such as air, water, and soil pollution; product exposure chemicals; climate change; and ultraviolet radiation, contributed to more than 100 different diseases or injuries (World Health Organization, 2016). As climate change is likely to increase these hazards, managing the concepts of sustainability and climate change, and their relationship with people's health and well-being, is fundamental for health systems and professionals (Barna et al., 2012; Goodman, 2011). Sustainability in health care is designing and delivering health care that meets today's health and health care needs of individuals and populations without compromising the ability of future generations to meet their own health and health care needs; this requires the provision of health care that recognizes and respects the dependence of our health on the earth's ecosystems, without resulting in unfair or disproportional impacts within society (NurSus.eu).

\section{BACKGROUND}

In 2015, the Health and Climate Change Commission of "The Lancet" presented a report stating that "addressing climate change may be the greatest opportunity for global public health in the 21st century" (Bloomfield et al., 2010; Wang and Horton, 2015). In addition, the report highlights the key role that the health community must play on the road to that transition (Watts et al., 2015). The priorities suggested for professionals in the health community in the face of climate change include: promoting climate agreements, strengthening the adaptive capacity of health systems, using scientific evidence for adopting measures, and promoting the participation of other professionals (Springmann et al., 2016). 
Specifically, the nursing profession is an agent of change and can play a central role in detecting problems and implementing actions that have an impact on individual and collective health (Fenero, 2016). Nursing students, must acquire an understanding of sustainability, together with knowledge and skills to act in a professional capacity and communicate the problem to society (Anaker and Elf, 2014; Campbell, 2008; Goodman, 2011; Richardson et al., 2014), by including a series of key competencies for sustainability in the curricula.

Education in sustainable development (ESD) has long been recognised by many initiatives under the U.N. Decade of Education for Sustainable Development (20052014). The Global Action Programme on ESD was discussed at UNESCO's 37th session of the General Conference (United Nations Educational Scientific and Cultural Organization (UNESCO), 2014). Addressing climate change requires specific training and action for mitigation and adaptation directed to technical and productive key sectors (Richardson et al., 2016).

Despite the widely acknowledged importance of both ESD and a more sustainable healthcare sector, there is limited European literature on nursing and climate change or sustainability; nursing students are poorly prepared to understand the connections between resources, climate change, sustainability, and health (Goodman, 2010; Kirk, 2002). Sustainability can be embedded in the healthcare curriculum through a range of learning opportunities; for example, in the context of public health and health inequalities, poverty, food security, infectious diseases, and skills development (Richardson et al., 2014; Richardson et al., 2016).

The use of digital technologies and resources has grown rapidly in recent decades, and teaching via E-learning has been widely adopted as a continuous learning method for nursing staff. Among the advantages of teaching via E-learning are flexibility, selfregulation, and time savings (Bloomfield and Jones, 2013; Button et al., 2014; Wu et al., 2010). Furthermore, E-learning has been promoted for its ability to engage learners and customise the learning process, and evidence supports its use for clinical skill acquisition (Bloomfield et al., 2010; Bloomfield and Jones, 2013).

However, this type of teaching process requires that the teacher is aware of factors that influence the success of digital technology in the learning process, in order to incorporate minimum quality requirements. Selection of digital materials can often be made on the basis of ease of access, rather than the ability of the materials to meet 
appropriate educational aims, thus, compromising quality and jeopardising success of learning (García-Barrera, 2016). In this sense, the analysis of certain dimensions of the digital resources, by means of credibility indicators that allow evaluation of their quality and educational utility, is recommended (Ehlers and Hilera, 2012; Rivero, 2013). Many authors highlight the need to generate an instrument with unified criteria to facilitate the analysis of digital teaching materials (Flores and Rivero, 2014).

Based on this approach, a team from the universities of: Jaen (Spain), Plymouth (UK), Esslingen (Germany) and Maastricht (the Netherlands), is developing the NurSus TOOLKIT project (http://nursus.eu/). The objective of this project is to improve the level of knowledge, skills, and abilities regarding sustainability and the effects of climate change on the nursing profession, by developing new teaching and learning resources and disseminating and promoting good practices, with the help of information technologies. Within the framework of the NurSus project, a range of Digital Education Materials on environmental sustainability in Nursing were designed and tested.

The aim of the current study was to test and evaluate digital educational materials on environmental sustainability and health in the context of university nursing education in different European countries.

\section{METHODS}

\section{SAMPLE}

The sampling was purposive, designed to gain feedback from a range of people most likely accessing the materials in the UK, Spain, and Germany:

- Nursing Degree students from the Universities of Plymouth, Jaen and Esslingen, were selected by each institution according to appropriate opportunities within the curriculum and depending on the materials tested.

- Nursing professionals: those working in life-long learning institutions (Primary Health Care or Hospitals) or in research centres with postgraduate studies (Master or PhD).

- Nursing degree teachers: with 3 or more years teaching Community Health or related.

- External expert advisors from Europe who had taken part in a priority setting exercise for the NurSusTOOLKIT topics.

- Technical Experts in evaluating digital learning and teaching materials in Higher Education. 


\section{EVALUATION QUESTIONNAIRE}

A modified and authorised questionnaire from the Spanish Standard for the assessment of Digital Educational Material Quality (COdA) was used (FernándezPampillón et al., 2012). The COdA tool enables the evaluation of the quality of Digital Educational Material (DEM) at University level with three dimensions: Didactical, Technological, and Accessibility. It is a validated tool to assess and guide the creation of educational and technologically effective digital teaching material; the COdA tool was evaluated for validity and reliability (Arús-Hita et al., 2011).

The original COdA questionnaire consists of eleven criteria: coherence/understandability, content quality, ability to generate learning, adaptability, interactivity, motivation, format and design, reusability, portability, interface accessibility, and content accessibility. Each criterion is broken down into sub-criteria, which are scored from 0 (when the sub-criterion was not reached), to 10 (if it was fully reached). The Ratio per criterion and the Global ratio were calculated using the scores from the COdA questionnaire. Based on the Global ratio, a quality categorisation of the materials is defined, including ratings of excellent (ratio $\geq 9$ ), very good ( $9>$ ratio $\geq 8$ ), good $(8>$ ratio $\geq 6)$, not good enough $(6>$ ratio $\geq 4)$, and poor $(4>$ ratio $\geq 0)$. The minimum quality for a DEM is set to a value higher or equal to 6 .

In order to carry out a pre-use evaluation of the DEM, two modalities of the COdA tool for two user profiles were designed, targeting students and professionals (teachers, clinical professionals, and expert advisors). 15 experts in evaluation of DEM rated the content validity to assess the desired construct of the two modalities of the COdA tool by a questionnaire that using a Likert scale (from 1 to 5 ) assessed utility, clarity, completeness, precision and usability for each criterion Technical experts in digital educational materials evaluation used the whole original version of COdA.

In addition to the COdA questionnaire, sociodemographic data were collected from the participants, and two opened-ended questions were included inviting comments about the experience with the use of the materials and proposals to improve them. A content analysis was conducted for this qualitative data.

Native speakers translated the questionnaires into English and German. These translations were translated back to Spanish by other native speakers and modifications were made where necessary. According to independent experts (COdA authors), the final versions of COdA represented adequate translations of the Spanish original. Finally, to assess the content validity of the English and German versions it carried out the same process described above for the Spanish versions. 


\section{PROCESS}

A piloting and validation process was conducted between December 2015 and January 2016 to check the process, the materials and the questionnaire. The results of the pilot process contributed to improvements in the design of the Prototype Materials. The materials evaluated in each country were the same and had the same structure but adapted to the characteristics, context and more prevalent health problems of each of them. Each set of materials included: description of materials, teacher guidance, lecture, lecture PowerPoint, lecture notes, activities, and resources.

\section{DATA COLLECTION}

Data collection took place between February and May 2016 at the Universities of Plymouth, Jaen and Esslingen.

The evaluation process varied according to the participant profile; an email was sent to professionals, with a letter of the evaluation process presentation, an informed consent document, the COdA questionnaire, and guidelines for completing it. Once they returned the signed consent document, they were sent the teaching and learning materials for assessment. For students, the evaluation was carried out in a different way: after signing the informed consent document, the students worked with the materials during a scheduled learning session. The students filled in the questionnaire online (in Jaen) or received the questionnaire in paper form (in Plymouth and Esslingen Universities).

Ethical approval for the study was granted by all Universities (Plymouth, Jaen and Esslingen) from their respective Ethic Commettees, before the evaluation process. The confidentiality of personal data was maintained. Guidelines for computer-assisted data processing were followed.

\section{STATISTICAL ANALYSES}

Data were tabulated and coded for statistical analysis. Cronbach's alpha coefficient was applied to obtain the reliability index of the questionnaires. A descriptive analysis was made by calculating the means and standard deviations, or median and interquartile ranges for ordinal and quantitative variables, and the frequencies and percentages for categorical variables.

The assumption of a normal distribution was evaluated using the Kolmogorov-Smirnov test. The variables "Global ratio" and "Ratios of each criterion" (Criterion ratio) in students and professionals per country were adjusted to the standard distribution, 
except the criterion of portability, which had no normal distribution for students and professionals of the three universities. The Pearson $R$ test was used for the analysis of correlations between age and the Global ratio in students. The assumptions of equality of means across groups were tested using Student's t-test for the association of the Global ratio with gender in students; association of the Global ratio and each criterion ratio (except for portability) with the user profile; and association of the Global ratio and each of the criterion ratios with the university that evaluates among professionals. Mann-Whitney $U$ test was used for the portability criterion (it had no normal distribution), while ANOVA was used for the association of Global ratio with the age range of the students and for the association of the Global ratio and each of the criterion ratio of students with the university, except for the Portability criterion, where the Kruskall-Wallis test was used. When the distributions did not meet the assumptions for calculating ANOVAs, the robust Welch test was used for post hoc tests. The standardisation effect size was measured by Hedges $g$ and its $95 \%$ confidence interval (because the large differences between $\mathrm{N}$ groups). Two-tailed tests were used, considering a value of $p<0.05$ as statistically significant. Analyses were performed using IBM SPSS 21.0.

\section{RESULTS}

\section{PARTICIPANTS: SOCIODEMOGRAPHIC CHARACTERISTICS}

The total sample of users who evaluated the digital educational materials consisted of 321 participants (299 students, 20 professionals, and 2 technical experts).

Table 1 shows the characteristics of the students participating in the assessment of the materials. $81.5 \%$ of students are women, which corresponds to the high proportion of females undertaking the degree in Nursing. Students median age was 22 years $\left(P_{25}: 20.0 ; P_{75}: 26.75\right)$, and they mainly $(47.8 \%)$ belong to second year of the Degree in Nursing.

The group of professional evaluators consisted of 22 participants, (12 belonging to the University of Jaen and 10 to the University of Plymouth), with different profiles: 8 teachers (Jaen: 4; Plymouth: 4); 8 clinical professionals (Jaen: 4; Plymouth: 4); 4 expert advisors (Jaen: 3; Plymouth: 1); and 2 technical experts (Jaen: 1; Plymouth: 1). It should be noted that, in Spain, the technical expert is the main author of the original version of the COdA tool.

In the reliability analysis of the COdA questionnaire used for each profile, we obtained a Cronbach's $\alpha$ of 0.97 for the profile of students and of 0.98 in the questionnaire for 
the profile of professionals. All the Cronbach $\alpha$ values for the two modalities of COdA tool for each country were higher than 0.92 .

\section{QUANTITATIVE ANALYSIS}

\section{Analysis per application profile}

The score for the overall evaluation of educational materials by students was $7.98 \pm$ 1.28 points (see table 2). The quality criteria of the DEMs that received the best evaluations from students were: Ability to generate learning (8.40 \pm 1.40$)$, Quality of contents $(8.15 \pm 1.74)$, and Format and design $(8.13 \pm 1.45)$. It highlighted the difficulty of evaluating the Portability criterion, since the materials were tested in the context of a class session, so Portability in other devices was not tested, obtaining $25.5 \%$ of missing values from the University of Plymouth and $69 \%$ from the University of Esslingen.

In the group of students, no correlation was found between age and the Global ratio ( $r$ $=-0.021 \mathrm{p}=0.75)$. Furthermore, the mean differences between the different age groups were not statistically significant (Welch $=0.44, p=0.72$ ). The overall assessment by female students was $7.99 \pm 1.03$, and that of male students was $8.01 \pm$ 1.28 , however, this difference was not statistically significant $(t=-0.09, p=0.93)$.

The professionals evaluated the materials with $8.50 \pm 1.17$ points, giving high scores to the criteria Portability of the materials $(9.35 \pm 1.35)$, Quality of contents $(9.30 \pm 1.27)$, and Format and design $(8.76 \pm 1.39)$; therefore the educational materials were catalogued as achieving very good or excellent quality. However, the lowest criterion was the Ability to generate learning $(7.42 \pm 0.81)$ (See Table 2).

For the profile of technical experts, the evaluation tool included two additional criteria: the accessibility of the interface and the accessibility of the content. Several criteria were qualified as excellent (ratio $\geq 9$ ). The Accessibility of the content was the criterion evaluated worst by both experts (see table 2).

Students scored Global Ratio lower than professionals, with a difference of -0.52 (1.10-0.070), although this difference was not statistically significant $(p=0.083)$. The Ability to generate learning criterion was unique, in that the students scored this higher than the professionals, with a mean difference of $0.84(0.22-1.47)$, which is statistically significant $(p=0.008)$. The criteria in which students scored lower than professionals, with statistically significant differences were: Coherence/Understandability (mean difference: -1.08 ; -1.83 to -0.34$)(p=0.004)$; Content Quality (mean difference: -1.25; - 
2.03 to -0.47$)(p=0.002$ ); and Format and design (mean difference: $-0.71 ;-1.37$ to $0.047)(p=0.036)$.

\section{Analysis of criteria per University}

Table 3 shows Mean score of the Global Ratio and the different quality criteria that the students of the different universities awarded to the educational materials evaluated.

In the overall assessment performed by the students, statistically significant differences were found between the three universities (Welch: 11.69, $p<0.001$ ). Specifically, the students' score at the University of Jaen was the highest, with $8.29 \pm 1.02$ points (8.138.45), followed by that of Esslingen students, with $7.98 \pm 0.69$ (7.40-8.55), and those of Plymouth, with $7.30 \pm 1.56$ (6.93-7.67), although only the differences between Jaen and Plymouth were statistically significant $(p<0.001)$. The standardised effect size (Hedges g) for Jaen-Plymouth was high; 0.81 (0.52 to 1.10) (Table 4).

Jaen students gave a higher score than Esslingen and Plymouth students for all specific criteria except the Portability criterion. We obtained significant differences in the following, Coherence/Understandability: Welch 26,56, $p<0,001$; Content quality: Welch 10,20, $p<0,001$; Ability to generate learning: Welch 23,51, $p<0,001$; Adaptability: Welch 11,16, $p<0,001$; Interactivity: Welch 12,76, $p<0,001$; Motivation: Welch 3,63, $p=$ 0,03 , Format and design: Welch 8.70, $p=0.001$; and Competences: Welch 20.23, $\mathrm{p}<0.001$, whereas for the Portability criterion there were no such differences (KruskallWallis test, $p=0.81$ ).

With respect to the professional profile, those in Plymouth performed slightly higher on a mean overall assessment ( $8.85 \pm 1.30$ points) than those in Jaen $(8.21 \pm 1.03$ points) (see Table 5$)$, although this difference was not statistically significant $(p=0.21)$. For the mean differences for the criteria, we found that higher scores were awarded by Plymouth professionals for all criteria, but that this difference was only statistically significant $(p=0.03)$ for the criterion Ability to generate learning, with a high standardised effect size (Hedges $\mathrm{g})$ : $1.00(\mathrm{Cl}=0.06-1.93)$.

\section{QUALITATIVE ANALYSIS}

The content analysis of qualitative questions highlighted the ability of materials to "generate reflection" on environmental issues related to nurse practice. Students believed that the materials "generate critical thinking" not only for their performance as future nursing professionals, but also as responsible and concerned citizens with respect to environmental problems. Both teachers and students reported that the 
materials have a "motivating and stimulating" design. Expert advisors emphasised "clarity and aesthetics" as strengths of the materials.

However, new instructions were proposed on the use of the platform and the sequence recommended for the use of the materials. Students proposed an improved relationship between the theory and concepts of environmental sustainability to nursing practice. To do this, they proposed the inclusion of activities that facilitate the "connection between concepts and real contexts", through case studies or problem-solving activities.

Students, professionals and experts suggested the use of "more interactive resources" for the DEM. Teachers also argued for higher interactivity, suggesting including resources that facilitate communication between students and teachers. Finally, the teachers recommended adding some type of evaluation of the learning process for the students' use.

\section{DISCUSSION}

It is important to evaluate the quality of e-learning materials prior to wide use, to determine which criteria need improvement. The digital educative materials evaluated in this study obtained high scores from both students and professionals, indicating very good quality.

The quality criteria that received the best evaluations from the students were: Ability to generate learning; Quality of contents; and Format and design. Those findings are similar to others studies on the use of e-learning for nursing degree students (Bloomfield and Jones, 2013; Button et al., 2014; Hoffman et al., 2011), in which students were more motivated by this learning approach and achieved deeper learning and acquisition of clinical skills. Jeffries (2005) found that students considered that digital material enabled them to engage in active learning. This was similar to our students' perceptions of e-learning materials helping them to generate critical thinking. Bloomfield and Jones (2013) found approach and structure of educative materials to be the criteria that received higher evaluations, and this is also similar to the findings from our study. In others studies, nursing students reported the quality and usefulness of the Web-enhanced material for developing cognitive skills, such as clinical reasoning, problem solving, and decision making (Creedy et al., 2007; Hoffman et al., 2011).

The professionals scored the criteria: Quality of contents, and Format and design, as either very good or excellent; however; the lowest criterion was the Ability to generate learning. Similar findings were reported by de Góes et al., (2011), where teachers and nurses that evaluated a virtual learning instrument for students considered that it had 
high quality in design and contents but a low capacity to generate learning. If the materials were considered of high quality, teachers' evaluation of the materials' poor utility regarding acquisition of learning could be explained by the teachers' low experience and motivation regarding the use of e-learning material, as has been reported in others studies (Button et al., 2014; Pfefferle et al., 2010). Pfefferle et al. (2010) noted a change in teachers' attitudes to e-learning after they were trained to use it and to implement its use in teaching, especially in relation to their perception of the capacity of e-learning to improve the learning performance of students. In addition, that idea is reinforced by our study, where we found that the students scored the criterion Ability to generate learning higher than the professionals, with a statistically significant difference. We must recognise the effort required of teachers in the introduction of new teaching methodology, which requires changes to both pedagogy and practice; Koch (2014) states the need to re-define the educator's role in light of e-learning, with new competencies and functions.

In our study, the students proposed providing a better link between the theory of environmental sustainability and nursing practice. In another study (Bloomfield and Jones, 2013) students considered e-learning to be a useful learning strategy but that it required a greater degree of training in clinical skills, as such, they argued that digital materials could not replace classes involving practical procedures. Moreover, both students and teachers also proposed the use of "more interactive resources" and the incorporation of other activities, similar to the findings of de Góes et al. (2011).

The NurSusTOOLKIT will be useful for nursing professionals interested in acquiring new competences in environmental sustainability and health for clinical practice; Lahti et al. (2014) reported that nurses could transfer new knowledge obtained from continuing education through e-learning to daily practice.

We found differences between students and professionals in the different countries; students from Jaen and professionals from Plymouth evaluated the materials being of higher quality. However, we must have caution in drawing conclusions about the differences between countries. It cannot argue that the quality of materials from Jaen is higher than the others, since they were not evaluated by the same students. For the same reason, we cannot state that the materials from Plymouth give more confidence to educators about their capacity to generate learning in students.

Given the current state of research and practice in the field of quality in e-learning, it is established that is necessary to apply a quality model for e-learning (Ehlers and Hilera, 2012). Several e-quality frameworks offer a structured set of factors and benchmarks 
as a tool for practical quality with e-learning in institutions. The e-learning maturity model (Marshall, 2012) assesses five dimensions (Learning, Development, Support, Evaluation, and Organisation). Similar factors are considered in the e-quality framework reported by Masoumi and Lindström (2012): Pedagogical factor, Technological factor, Instructional design factor, Student support, Faculty support, Evaluation factor, and Institutional factor. Therefore, the use of the COdA tool fits perfectly to these quality models for e-learning, since it has both the necessary didactic and technologic aspects. There are other tools for assessing the quality of digital learning materials (Leacock and Nesbit, 2007; Marcelo and Zapata, 2008), however, the COdA tool is included in the Spanish Standard for the Assessment of Digital Educational Material Quality (Fernández-Pampillón, 2014). The COdA tool is based on the Learning Object Review Instrument (LORI) (Leacock and Nesbit, 2007), being its specific purpose to support evaluation of multimedia learning objects; however, LORI was not adequate to guide faculty in the adaptation of teaching materials to learning objects; the COdA tool provides guidance for the construction of digital learning materials through self-evaluation during the elaboration process, both from a pedagogic and a technological point of view, without requiring to have extensive computer skills (Arús-Hita et al., 2011).

This research contributes to a better understanding of how the topics of climate change and sustainability can be communicated to nurses through digital teaching and learning materials. The results have shaped an Open Access platform of education resources designed to increase knowledge and skills in health and sustainability (see http://nursus.eu/). After having reviewed the learning materials in our study, we will continue to determine the efficacy of e-learning materials on sustainability and health in nursing students in different European countries. As concluded in several systematic reviews (Du et al., 2013; Lahti et al., 2014) on the impact of e-learning on nurses' and student nurses' knowledge, skill, and satisfaction, it is important to develop and evaluate methods for education in nursing, and these studies should be conducted to show effectiveness.

\section{CONCLUSIONS}

Issues related to e-learning experiences on sustainability, environmental and health in nursing students have not previously been addressed. This study makes a significant contribution to the design and evaluation of educative materials on nursing and sustainability. Materials can be freely accessed on the NurSusTOOLKIT online platform (http://nursus.eu/). 
It is necessary to continue this approach to evaluate the effectiveness of the DEM in promoting knowledge of sustainability in the nursing learning process, as well as evaluating the experiences of teachers while they are using them.

\section{REFERENCES}

Anaker, A., Elf, M., 2014. Sustainability in nursing: A concept analysis. Scandinavian Journal of Caring Science 28 (2), 381-389. doi:10.1111/scs.12121

Arús-Hita, J., Fernández-Pampillón, A. M., Lahoz, J. M., Domínguez, E., de Armas, A. I., 2011. Learning object management for IT-illiterate instructors. Proceedings of 3rd International Conference on Education and New Learning Technologies (EDULEARN11). International Association of Technology, Education and Development (IATED), Valencia. Retrieved from https://library.iated.org/publications/EDULEARN11

Barna, S., Goodman, B., Mortimer, F., 2012. The health effects of climate change: What does a nurse need to know? Nurse Education Today 32 (7), 765-771. doi:10.1016/j.nedt.2012.05.012

Bloomfield, J. G., Jones, A., 2013. Using e-learning to support clinical skills acquisition: Exploring the experiences and perceptions of graduate first-year pre-registration nursing students - A mixed method study. Nurse Education Today 33 (12), 16051611. doi:10.1016/j.nedt.2013.01.024

Bloomfield, J., Roberts, J., While, A., 2010. The effect of computer-assisted learning versus conventional teaching methods on the acquisition and retention of handwashing theory and skills in pre-qualification nursing students: A randomised controlled trial. International Journal of Nursing Studies $47 \quad$ (3), 287-294. doi:10.1016/j.jinurstu.2009.08.003

Button, D., Harrington, A., Belan, I., 2014. E-learning \& information communication technology (ICT) in nursing education: A review of the literature. Nurse Education Today 34 (10), 1311-1323. doi:http://dx.doi.org/10.1016/j.nedt.2013.05.002

Campbell, S., 2008. Nursing the planet. Primary Health Care 18 (3), 41-48.

Creedy, D. K., Mitchell, M., Seaton-Sykes, P., Cooke, M., Patterson, E., Purcell, C., Weeks, P., 2007. Evaluating a web-enhanced bachelor of nursing curriculum: Perspectives of third-year students. Journal of Nursing Education 46 (10), 460-467. Retrieved from http://search.ebscohost.com/login.aspx?direct=true\&db=ccm\&AN=106200811\&site=eh ost-live\&scope $=$ site

de Góes, F. d. S. N., Fonseca, L. M. M., Furtado, M. C. d. C., Leite, A. M., Scochi, C. G. S., 2011. Evaluation of the virtual learning object 'diagnostic reasoning in nursing applied to preterm newborns'. Revista Latino-Americana de Enfermagem 19 (4), 894-901. doi:10.1590/S0104-11692011000400007

Du, S., Liu, Z., Liu, S., Yin, H., Xu, G., Zhang, H., Wang, A., 2013. Web-based distance learning for nurse education: A systematic review. International Nursing Review 60 (2), 167-177. doi:10.1111/inr.12015

Ehlers, U. -D., Hilera, J. R., 2012. Special issue on quality in e-learning. Journal of Computer Assisted Learning 28 (1), 1-3. doi:10.1111/j.1365-2729.2011.00448.x

Fenero, A., 2016. Un motor de cambio social. Enfermeria Facultativa, XX (231), 26-27. Retrieved from https://www.consejogeneralenfermeria.org/index.php/sala-de- 
prensa/revista-colegial/send/29-revista-enfermeria-facultativa/573-enfermeriafacultativa-numero-231

Fernández-Pampillón, A., Domínguez, E., de Armas, I., 2012. Herramienta para la revisión de la calidad de objetos de aprendizaje universitarios (COdA): Guía del usuario. v.1.1. Informe técnico. Retrieved from http://eprints.ucm.es/12533/

Fernández-Pampillón, A. M., 2014. Desarrollo de una norma española de calidad de materiales educativos digitales. Vaep-Rita, 2(1), 49-56. Retrieved from http://rita.det.uvigo.es/VAEPRITA/index.php?content=Num_Pub\&idiom=Es\&visualiza= $3 \&$ volumen $=2 \&$ numero $=1 \&$ articulo $=9$

Flores, H. C., Rivero, P., 2014. How do teachers select digital resources for teaching history? CLIO. History and History Teaching 40. Retrieved from http://clio.rediris.es/n40/articulos/FloresRivero2014.pdf.

Galloway, D. L., 2005. Evaluating distance delivery and e-learning is Kirkpatrick's model relevant? Performance Improvement 44 (4), 21-27. doi:10.1002/pfi.4140440407

García-Barrera, A., 2016. Evaluación de recursos tecnológicos didácticos mediante erúbricas. Revista de Educación Distancia 49. Retrieved from http://revistas.um.es/red/article/view/257691 DOI: http://dx.doi.org/10.6018/red/49/13??

Goodman B, R. J., 2010. Climate change, sustainability and health in UK higher education: The challenges for nursing. In Jones P, Selby D, Sterling S. (Ed.), Sustainability education perspectives and practice across higher education. Earthscan: London, pp. 109-132.

Goodman, B., 2011. The need for a 'sustainability curriculum' in nurse education. Nurse Education Today 31 (8), 733-737. doi:10.1016/j.nedt.2010.12.010

Hoffman, K., Dempsey, J., Levett-Jones, T., Noble, D., Hickey, N., Jeong, S., ... Norton, C., 2011. The design and implementation of an interactive computerised decision support framework (ICDSF) as a strategy to improve nursing students' clinical reasoning skills. Nurse Education Today 31 (6), 587-594. doi:10.1016/j.nedt.2010.10.012

Jeffries, P. R., 2005. Development and testing of a hyperlearning model for design of an online critical care course. Journal of Nursing Education 44 (8), 366-372. Retrieved from http://search.ebscohost.com/login.aspx?direct=true\&db=ccm\&AN=106524333\&site=eh ost-live\&scope $=$ site

Kirk M., 2002. The impact of globalization and environmental change on health: Challenges for nurse education. Nurse Education Today 22 (1), 60-71. https://dx.doi.org/10.1054/nedt.2001.0720

Koch, L. F., 2014. The nursing educator's role in e-learning: A literature review. Nurse Education Today 34 (11), 1382-1387. doi:10.1016/j.nedt.2014.04.002

Lahti, M., Kontio, R., Pitkänen, A., Välimäki, M., 2014. Knowledge transfer from an e-learning course to clinical practice. Nurse Education Today 34(5), 842-847. doi:http://dx.doi.org/10.1016/i.nedt.2013.09.003

Leacock, T. L., Nesbit, J. C., 2007. A framework for evaluating the quality of multimedia learning resources. Educational Technology \& Socity 10 (2), 44-59.

Marcelo, C., Zapata, M., 2008. Questionnaire "quality assessment for full teaching training programmes through open and distance learning strategies'. methodology and indicators description of use. RED, Revista de Educación Distancia, Monográfico VII.

Marshall, S., 2012. Improving the quality of e-learning: Lessons from the eMM. Journal of Computer Assisted Learning 28 (1), 65-78. doi:10.1111/j.1365-2729.2011.00443.x 
Masoumi, D., Lindström, B., 2012. Quality in e-learning: A framework for promoting and assuring quality in virtual institutions. Journal of Computer Assisted Learning 28 (1), 27-41. doi:10.1111/j.1365-2729.2011.00440.x

Pfefferle, P. I., Van den Stock, E., Nauerth, A., 2010. The LEONARDO-DA-VINCI pilot project 'e-learning-assistant' -- situation-based learning in nursing education. Nurse Education Today 30 (5), 411-419. doi:10.1016/j.nedt.2009.09.014

Richardson, J., Grose, J., Doman, M., Kelsey, J., 2014. The use of evidence-informed sustainability scenarios in the nursing curriculum: Development and evaluation of teaching methods. Nurse Education Today 34 (4), 490-493. doi:10.1016/j.nedt.2013.07.007

Richardson, J., Heidenreich, T., Álvarez-Nieto, C., Fasseur, F., Grose, J., Huss, N., ... .Schweizer, A., 2016. Including sustainability issues in nurse education: a comparative study of first year student nurses' attitudes in four European countries. Nurse Education Today 37, 15-20. doi:10.1016/j.nedt.2015.11.005

Rivero, I., 2013. Criterios para seleccionar tecnologías educativas y estrategias didácticas en el colegio Guillermo León Valencia. Educación y Ciencia, 16, 37-52. Retrieved from http://revistas.uptc.edu.co/revistas/index.php/educacion_y_ciencia/article/view/3239.

Springmann, M., Mason-D'Croz, D., Robison, S., Garnett, T., Godfray, H. C. J., Gollin, D., ... Scarborough, P., 2016. Global and regional health effects of future food production under climate change: A modelling study. Lancet 387 (10031), 1937-1946. doi:https://doi.org/10.1016/S0140-6736(15)01156-3

United Nations Educational Scientific and Cultural Organization (UNESCO)., 2014. Records of the general conference. 37th session. Paris. Retrieved from http://unesdoc.unesco.org/images/0022/002261/226162e.pdf

Wang, H., Horton, R., 2015. Tackling climate change: The greatest opportunity for global health. Lancet 386 (10006), 1789-1799. doi:https://doi.org/10.1016/S01406736(15)60931-X

Watts, N., Adger, W. N., Agnolucci, P., Blackstock, J., Byass, P., Cai, W., ... Costello, A., 2015. Health and climate change: Policy responses to protect public health. Lancet 386 (10006), 1861-1914. doi:10.1016/S0140-6736(15)60854-6

World Health Organization, 2016. 10 facts on preventing disease through healthy environments. Retrieved from http://www.who.int/features/factfiles/environmentaldisease-burden/en/

Wu, J., Tennyson, R. D., Hsia, T., 2010. A study of student satisfaction in a blended e-learning system environment. Computers \& Education 55 (1), 155-164. doi:10.1016/j.compedu.2009.12.012

Web references

NurSus.eu http://nursus.eu/interim-report-august-2015-a-delphi-study-and-thematicanalyses-of-curricula-to-identify-opportunities-for-embedding-sustainability-in-nursingcurricula/ (accessed 19 September 2017) 